\title{
Projetos de pesquisa e extensão: contribuições para formação de professores de matemática através do estágio supervisionado
}

\section{Research and Extension Projects: Contributions to Mathematics Teacher Training through Supervised Internship}

\author{
José Ronaldo Melo $^{1} *$
}

\begin{abstract}
RESUMO
Esse texto tem por objetivo discutir a participação de alunos dos cursos de Licenciatura em Matemática da Universidade Federal do Acre (UFAC) em projetos de extensão e de pesquisa que tenham como foco a prática pedagógica da Matemática escolar e de que forma essa participação poderá se constituir como campo do Estágio Curricular Supervisionado desses graduandos. Para isso, descrevemos a visão de Estágio Curricular Supervisionado presente no atual projeto pedagógico curricular - PPC do curso de Matemática da instituição, mostrando que esse importante componente curricular não deve ficar restrito a simples cumprimento de exigências burocráticas e acadêmicas, mas constituir-se de fato como oportunidade de crescimento pessoal e profissional e como instrumento de integração entre as instituições responsáveis pela formação - universidade, escola e comunidade, favorecendo a construção de uma identidade profissional voltada para uma prática docente que efetivamente possa contribuir para a melhoria do ensino de Matemática nas escolas de Educação Básica.
\end{abstract}

Palavras-chave: Extensão; Pesquisa; Estágio Curricular Supervisionado; Prática docente.

\begin{abstract}
This text aims to discuss the participation of students from the Mathematics Degree courses at the Federal University of Acre (UFAC) in extension and research projects that focus on the pedagogical practice of school Mathematics and how this participation can be constituted. as a field of the Supervised Curricular Internship of these undergraduates. For this, we describe the vision of Supervised Curricular Internship present in the current curricular pedagogical project - PPC of the institution's Mathematics course, showing that this important curricular component should not be restricted to simple compliance with bureaucratic and academic requirements, but actually constitute itself as an opportunity for personal and professional growth and as an instrument of integration between the institutions responsible for training - university, school and community, favoring the construction of a professional identity focused on a teaching practice that can effectively contribute to the improvement of mathematics teaching in schools of Basic Education.
\end{abstract}

Keywords: Extension; Search; Supervised internship; Teaching practice.

\footnotetext{
${ }^{1}$ Professor do Centro de Ciências Exatas e Tecnológicas (CCET) da Universidade Federal do Acre (UFAC) *ronaldo.ufac @ gmail.com. Tutor do Programa de Educação Tutorial (PET): Conexões de Saberes em Matemática
} 


\section{INTRODUÇÃO}

O estágio supervisionado na formação docente tem sido alvo de grandes debates apontando algumas dificuldades, mas também possibilidades de transformações no cotidiano desses profissionais. Este é um momento particular da formação em que o aluno pode vivenciar uma diversidade de experiências e conhecer melhor seu campo de atuação. De acordo com Pimenta e Lima (2004) "o estágio é o eixo central na formação de professores, pois é através dele que o profissional conhece os aspectos indispensáveis para a formação da construção da identidade e dos saberes do dia a dia". Para isso parece razoável que a escola de formação ofereça uma diversidade de possibilidades visando o desenvolvimento pleno do formando.

Educadores como Silva (2005) argumentam que no cotidiano acadêmico é perceptível que os graduandos se envolvam com muita disposição e ânimo quando a universidade lhes proporciona a participação em que consiga colocar conhecimentos teóricos em prática, acompanhados de um profissional supervisor ou quando possui uma instituição conveniada que estão em permanente contato com a universidade. Desta forma o estagiário pode aprender a observar e identificar os problemas, estar sempre absorvendo e buscando informações, questionando o que encontrou além de trocar informações com profissionais mais experientes.

De acordo com Francisco e Pereira (2004) o estágio surge como um processo fundamental na formação do estagiário, pois esta é forma de fazer a transição de aluno para professor. Este é um momento da formação em que o graduando pode vivenciar experiências, conhecendo melhor sua área de atuação. Para Guerra (1995) “o Estágio Supervisionado consiste em teoria e prática tendo em vista uma busca constante da realidade para uma elaboração conjunta do programa de trabalho na formação do educador", possibilitando ao aluno em processo de formação desenvolver uma postura de pesquisador através da observação e dos momentos de reflexão que poderão contribuir para reorganizar ações que possam reorientar a prática quando necessário.

Em nossa visão, pensar parte do componente curricular Estágio Supervisionado desenvolvido em projetos de ensino, pesquisa e extensão vinculados a grupos de pesquisa e programas de extensão, que tem como objeto de estudo e investigação a prática pedagógica da Matemática além de estar de acordo com o que aponta vários educadores do campo educacional, entre eles Silva (2007), Carvalho (1985), Cury (2004), Lima (1986), Pimenta (2004) e Gomes (1992), atende as recomendações prescritas na 
legislação federal disponíveis após o advento da Lei de Diretrizes e Bases da Educação Nacional, lei 9394/96, e nos atos normativos dela decorrente, sobretudo porque na maioria dos projetos que tem como foco a formação de professores de Matemática se faz necessária a presença de seus participantes nas escolas de Educação Básica, seja para se obter informações que se constituirão em dados para realização dessas pesquisas, seja para testar, no ambiente de sala de aula, matérias curriculares propostos com o intuito de favorecer uma melhor qualidade do ensino e da aprendizagem do aluno, ou para comunicações de resultados das pesquisas realizadas, tendo como foco o conhecimento da escola, especialmente o que acontece na sala de aula.

Particularmente, compreendemos que a formação docente acontece de múltiplas formas e a atuação dos formandos em projetos de ensino, pesquisa e extensão são, sobretudo, formas privilegiadas de mobilização para formação docente. Isso, em nossa visão, contempla o que preconiza o Parecer CNE/CP 27/2001 ao estabelecer que o estágio curricular supervisionado deva ser realizado em escolas de educação básica e vivenciado durante o curso de formação com tempo suficiente (CNE/CP 28/2001) para abordar as diferentes dimensões da atuação profissional. Para isso, estamos de acordo com Silva (2007) e defendemos ser necessário a existência "um projeto de estágio planejado e avaliado conjuntamente pela escola de formação inicial e a escola campo de estágio, com objetivos e tarefas claras e que as duas instituições se auxiliem mutuamente, o que pressupõe relações formais entre a instituição de ensino e as unidades dos sistemas de educação básica.

Esses "tempos na escola" devem ser diferentes e segundo os objetivos de cada momento de formação. Isso posto, acreditamos que o estágio não pode ficar sob a responsabilidade de um único professor da escola de formação, mas envolver uma atuação coletiva dos formadores". Desta forma, entendemos que as atividades de ensino, pesquisa e extensão desenvolvidas pelos alunos em projetos vinculados a grupos de estudos voltados para formação docente e endereçados a escola de Educação Básica, sob a responsabilidade de profissionais habilitados, constituem-se em momentos de formação profissional, seja pelo exercício direto in loco, seja pela presença participativa em ambientes próprios da área profissional. Compreendemos, portanto, que o componente curricular Estágio Supervisionado ao se constitui como uma das condições para a obtenção da licença para o exercício profissional deva a partir das formas e instrumentos disponíveis na instituição formadora oferecer oportunidades efetivando sob a supervisão 
de um professor experiente, um processo de ensino - aprendizagem em que poderá se tornar concreto e autônomo quando da profissionalização do estagiário (Parecer CNE 28/2001).

De outro modo, compreendemos que a disciplina Estágio Supervisionado pertence ao currículo do curso de formação de professores e deve ser pensada nesse âmbito. $\mathrm{O}$ preparo para o exercício do magistério não pode constituir-se tarefa exclusiva desta disciplina. Ela precisa estar articulada com os demais componentes curriculares do curso. Não pode ser isoladamente responsável pela qualificação profissional do professor (PICONEZ 1998, p.30). Assim, estamos de acordo com Pimenta e Lima (2004) quando argumenta que uma das finalidades do estágio é integrar o processo de formação do aluno, de modo a considerar o campo de atuação como objeto de análise, de investigação e de interpretação crítica, a partir dos nexos com as demais disciplinas do curso.

\section{INTERESSE PELO ESTÁGIO SUPERVISIONADO}

Durante o século XX a lógica dos cursos de formação de professores de Matemática assim como a lógica dos demais cursos de formação de educadores, historicamente fundamentava se segundo os pressupostos epistemológicos da racionalidade técnica, na qual a teoria tem pouca vinculação com a prática, ou seja, a prática fica subordinada a teoria. Nesta concepção "Os currículos são normativos, com a sequência de conhecimentos dos princípios científicos relevantes, seguidos da aplicação destes princípios e de um practicum, cujo objetivo é aplicar na prática cotidiana os princípios da ciência estudada.

Dentro da racionalidade técnica o desenvolvimento de competências profissionais deve colocar-se, portanto após o conhecimento científico básico e aplicado, pois não é possível aprender competências e capacidades de aplicação antes do conhecimento aplicável" [PEREZ GOMES, 1992, p. 98]. Assim o Estágio Supervisionado enquanto disciplina, argumenta Piconez (1998), foi sendo definida nos currículos dos cursos de licenciatura como uma disciplina de complementação, tendo como objetivo por em prática o que foi aprendido teoricamente pelo aluno para complementar a sua formação. A dicotomia entre teoria e prática, nesta concepção, fica evidente até na disposição da disciplina na matriz curricular.

O debate sobre as questões relacionadas à teoria e a prática na disciplina Estágio Supervisionado tonou-se, a partir da década de 1980 do século XX, objeto de estudo no 
campo educacional. Autores como Azevedo (1980), Candau \& Lellis (1983), Carvalho (1985), entre outros sugere de diferentes maneiras a unificação da teoria com a prática. Em suas reflexões estes autores argumentavam que as orientações para o encaminhamento do Estágio Supervisionado não privilegiavam as discussões entre educador e educando sobre o cotidiano da sala de aula, da escola e da comunidade. Assim, o conhecimento da realidade escolar através dos estágios não favorecia as reflexões sobre uma prática criativa e transformadora, nem possibilitava a reconstrução ou definição de teorias que sustentassem o trabalho do professor.

A partir da década de 1930 intensificam-se as preocupações com o Estágio Supervisionado, sobretudo com a instituição do curso de Didática em 1939, cuja concepção envolvia, conforme argumenta Silva (2007), estudos relativos à Metodologia de Ensino, relacionados com o planejamento, a execução da relação professor-aluno e a verificação de aprendizagens, conduzindo a uma possibilidade de Prática de Ensino, onde o estagiário poderia também apreender técnicas explanatórias que lhe permitiriam identificar e dimensionar os recursos comunitários, bem como estagiar em instituições que desenvolviam atividades relacionadas com sua futura habilitação. Contudo, é a partir do final do século XX que o Estágio Supervisionado passou a ser concebido como um espaço privilegiado na luta pela melhoria da formação docente, sobretudo na formação de professores de Matemática onde o discurso pela melhoria qualitativa do ensino dessa disciplina se tornou frequente e a busca da superação da dicotomia entre teoria e prática que se transformou num instrumento de luta pela qualidade do ensino e pela transformação do papel da disciplina Estágio Supervisionado que durante muito tempo conformou-se com o roteiro tradicional marcado pelo planejamento das atividades de ensino, pela observação e pela regência de sala de aula.

No campo da formação de professores para a área de Matemática esse debate foi impulsionado, nos últimos 20 anos, pelas reflexões promovidas pelas orientações de educadores e educadores matemáticos tendo como fundamento um novo paradigma determinado pelo avanço das tecnologias e pela chamada sociedade do conhecimento, apontado a necessidade de revisão de antigos conceitos e novas práticas para formação docente. É neste contexto que devemos, enquanto professor e pesquisador envolvido com questões relacionadas ao desenvolvimento profissional, identidade, formação docente e saberes que articulam teoria e prática, buscarmos novos caminhos e possibilidades que 
possam conduzir nossos estagiários para uma formação mais abrangente, com foco na melhoria da qualidade do ensino na Educação Básica.

\section{ESTÁGIO NA EXTENSÃO E NA PESQUISA}

Como mencionado na introdução desse estudo a questão que parece ser mais recorrente quanto aos esforços mobilizados na formação docente está nas diversas formas de relação teoria e prática que é de fato o que alicerça a formação, contudo é também objeto de muitas dúvidas quanto a sua forma de estrutura, organização e constituição. Estudos recentes como os que citamos anteriormente e reflexões realizadas no âmbito das instituições formadoras apontam para a necessidade de que o Estágio Supervisionado extrapole o limite da forma de como vem sendo majoritariamente praticado, geralmente através de ações isoladas com o aparente objetivo de cumprir a carga horária. Neste contexto, o Estágio Supervisionado passa a ter função fundamental que não deve ficar apenas restrito a levar os conhecimentos teóricos ao campo da prática, mas compreendêlos, reelaborá-los, pensando a realidade vivida pelo futuro professor. Dessa forma cabe aos agentes envolvidos refletir sobre as implicações que essa nova postura pode trazer para o trabalho do professor de Estágio Supervisionado e de que maneira isso pode ser efetivado.

A universidade, afirmam Pimenta e Lima (2004), é por excelência o espaço formativo da docência, ainda que não seja simples formar para o exercício da docência de qualidade. A expectativa é que neste espaço haja interação com a escola de Educação Básica. Assim, é imprescindível que a pesquisa e extensão enquanto espaço de investigação e exposições de conhecimentos se constituam em possibilidades de intervenção na formação docente. Para isso são necessários alguns procedimentos para comprovar essa interação como o retorno daquilo que foi pesquisado, elaborado e reelaborado a partir da presença do estagiário na escola de Educação Básica, em propostas de formação continuada para esta escola e a presença desta na universidade em propostas significativas de relato de experiências, por exemplo, ou ainda nas aulas de estágio com a apresentação e discussão de temas pedagógicos.

A legitimação da universidade como espaço de formação se concretiza, portanto, a partir destes procedimentos, tanto para o aluno estagiário como para aquele educador de educação, que recebe o aluno estagiário, pois ambos se "formam" na prática. Tem-se, portanto, na investigação sobre a escola e na escola, em todas as suas performances, uma 
concepção e uma possibilidade concreta que se pode levar a efeito como encaminhamento para o estágio curricular supervisionado. Ou seja, concebê-lo como pesquisa pressupõe o embate direto com a sala de aula, com o cotidiano da escola e com a legitimação, confirmação e ou transformação de aspectos teóricos construídos em disciplinas de formação específicas.

A inserção do estagiário na escola em atividades de pesquisa poderá seguir uma abordagem teórica - prática que, certamente, tornará o fazer pedagógico mais qualitativo, mais dinâmico e transformador. Isso poderá colaborar também com todos os aspectos que compõem a totalidade da escola: a gestão, as relações intra e extraescolares, o planejamento etc. É diante deste contexto que o colegiado do Curso de Matemática contemplou em seu Projeto Pedagógico, parte do componente curricular Estágio Supervisionado, como possibilidade de inserção do estagiário na escola básica através de atividades de extensão e de pesquisa vinculada a projetos que vem sendo desenvolvidos por professores que lecionam no curso. Interpretado o que preconiza o Parecer 02 de 19 de fevereiro de 2001 do CNE o colegiado do Curso de Matemática compreende que a Regência de classe pressupõe a iniciação profissional como um saber que busca orientarse por teorias de ensino-aprendizagem para responder às demandas colocadas pela prática pedagógica à qual se dirige.

Projetos de extensão estruturam atividades na forma de seminários, minicursos e oficinas para professores, alunos e demais comunidade escolar ou ainda grupos de educação não-formal sobre temas específicos de cada curso de licenciatura. Projetos de pesquisa podem favorecer um conjunto de propostas sobre a pesquisa educacional acerca de "inquietações" próprias do processo de ensino-aprendizagem e suas especificidades. Seguindo esta lógica os estagiários do Curso de Licenciatura em Matemática poderão, durante o desenvolvimento do componente curricular Estágio Supervisionado desenvolver atividades de monitórias e seminários voltados para o acompanhamento do trabalho de educadores que atuam em grupos de educação especial, educação de jovens e adultos, grupos da terceira idade etc. Desenvolvendo relatórios de atividades, seminários temáticos e outras possibilidades da realidade situacional da universidade e unidades escolares.

Assim, o componente curricular Estágio Supervisionado abrange, em nossa visão, o ensino, a pesquisa e extensão e nisso estamos de acordo com vários pensadores do campo educacional, entre eles Cury (2004), que defende que o Estágio supervisionado 
deve proporcionar ao estagiário a oportunidade de articulação entre o momento do saber e o momento do fazer, pois “O momento do saber não está separado do momento do fazer, e vice-versa, mas cada qual guarda sua própria dimensão epistemológica. O aprender a ser professor, dessa forma, é reconhecido como um saber profissional intencionado a uma ação docente nos sistemas de ensino".

O estágio curricular supervisionado é a disciplina na qual o estagiário deve vivenciar várias práticas e vários modos de ser professor. Conforme a LDB 9394/96 no seu artigo 13, os profissionais da educação deverão vivenciar da vida escolar de um modo geral, desde atividades de elaboração de proposta pedagógica da escola, até elaboração e cumprimento de planos de trabalho, seguido de atividades, como zelo pela aprendizagem do aluno, estabelecimento de estratégias de recuperação para alunos de menor rendimento, participação nos períodos de planejamento, avaliação e desenvolvimento profissional e, a colaboração em atividades de articulação da escola com as famílias e a comunidade.

\section{CONSIDERAÇÕES FINAIS}

No contexto apresentado neste trabalho, o Estágio Curricular Supervisionado, poderá acontecer em instituições de ensino público: municipais e estaduais, havendo também a possibilidade de acontecer em instituições não formais de ensino quando em atividades de extensão e pesquisa.

Considerando as possibilidades apresentadas e o que consta nos dispositivos legais, as atividades a serem planejadas para esse componente curricular deverá levar em consideração as discussões acumuladas e as experiências vivenciadas em alternativas presentes em projetos de ensino, pesquisa e extensão, desencadeando um processo de reflexão contínua de como poderá acontecer na prática o desenvolvimento desse componente curricular e, principalmente qual a sua concepção atual, pois não cabe mais repetir modalidades que legitimam a separação entre teoria e prática e ou concebê-lo como complementação aos conteúdos de formação específica.

Os professores que atuam neste componente curricular terão, portanto, como desafio, ir além do que majoritariamente vem sendo interpretado e praticado buscando formar professores de Matemática para a totalidade da Educação Básica. Deve, sobretudo, considerar processos de ensino e aprendizagem, conteúdos legitimados pela comunidade acadêmica e escolar, gestão, planejamento, relação com a comunidade, com os 
educadores e alunos, o que pressupõe encaminhamentos alternativos á forma tradicional, pautada pelo paradigma da racionalidade técnica. Para isso é necessário que a instituição formadora torne claro em sua legislação interna e em sua estrutura administrativa, mecanismos que possibilitem a regulamentação, desse importante componente curricular a partir de alternativas que possam de fato fortalecer a formação de seus educandos, contribuindo para a melhoria do ensino de Matemática da escola básica.

Deve considerar sobretudo, no processo de desenvolvimento, a promoção de articulações entre a formação teórica e a prática pedagógica, buscando o desenvolver habilidades necessárias à formação de professores de matemática para o exercício do magistério na Educação Básica. Deve também possibilitar ao aluno-professor o desenvolvimento de competências e habilidades necessárias para a prática docente, para a produção de saberes sobre ensinar matemática e para a reflexão sobre a atividade profissional, inserindo o futuro professor no campo da prática profissional $\mathrm{e}$ possibilitando-o atribuição de significados ao processo de ensino e aprendizagem, de maneira a tornar compreensíveis os significados e saberes construídos pelos alunos e suas implicações para sua atuação profissional.

Concordando com Fillos, e Macon (2011) “o Estágio Supervisionado deve ser visto por todos - acadêmicos, professores formadores nas universidades e professores regentes da educação básica - como espaço de diálogo, de desvelar caminhos, de superar barreiras, de favorecer melhores aprendizagens". Deve ser entendido, como reafirmação da escolha da profissão e de crescimento, constituição de uma identidade docente, a fim de que, ao seu término, os futuros professores possam estar seguros de que poderão desenvolver suas atividades profissionais.

\section{REFERÊNCIAS BIBLIOGRÁFICAS}

CARVALHO, I. M. O processo didático. Rio de Janeiro: FGV, 1985.

CURY, Carlos Roberto Jamil. Estágio Supervisionado na formação docente. In: Políticas Educacionais, práticas escolares e alternativas de inclusão escolar. São Paulo: DP \&A Editora.

FILLOS, Leoni Malinoski e MARCON, Luzia da Conceição Jorge. Estágio supervisionado em matemática: significados e saberes sobre a profissão docente. Congresso Nacional de Educação -EDUCERE. I Seminário Internacional de Representações Sociais, Subjetividade e Educação - SIRSSE. PUC, Curitiba, 2011. 
FRANCISCO, C. M. e PEREIRA, A.S. Supervisão e Sucesso do desempenho do aluno no estágio, 2004. Disponível em internet. http://www.efdeportes.com/efd69/aluno. htm. Acesso em 06 Jul. 2013.

GUERRA, Miriam Darlete Seade. Reflexões sobre um processo vivido em estágio supervisionado: Dos limites às possibilidades, 1995. Disponível em internet. http://www. anped.org. br/23/textos/0839t.PDF. Acesso em 05 Jul. 2013

LIMA, M ${ }^{\text {a }}$ do Socorro Lucena. A hora da prática: reflexões sobre o estágio supervisionado e a ação docente. 3a edição. CE: Editor Demócrito Rocha, 2002. São Paulo: EPU, 1986.

MEC. Lei de Diretrizes e Bases da Educação Nacional nº 9394/96. Brasília. 20 de dezembro de 1996.

. Conselho Federal de Educação. Parecer 349 de 1992.

Conselho Federal de Educação. Parecer 02 de 19 de fevereiro de 2001.

PÉREZ GOMES. A Formação dos professores da licenciatura. Portugal: Porto Editora 1992.

PICONEZ, S. A Prática de Ensino e o Estágio Supervisionado: A aproximação da Realidade Escolar e a Prática da Reflexão. In: PICONEZ, Stela (org) A prática de Ensino e o Estágio Supervisionado. 3a edição. Campinas, SP: Papirus, 1998.

PIMENTA, S.; SILVA, M. Estágio e docência. São Paulo: Cortez, 2004.

SILVA, Arlete Vieira da. Estágio Curricular Supervisionado no curso de licenciatura: momentos de vivência da profissão professor nas escolas de Educação Básica. Revista espaço acadêmico $-\mathrm{n}^{\circ} 73$ - junho/2007.

SILVA, S. A. P. dos S. Estágios Curriculares na Formação de Professores de Educação Física: o Ideal, o Real e o Possível. Revista Digital. Buenos Aires, v.10, n.82 p. 3-5, março, 2005.

\section{Recebido em: 03/01/2022}

